\title{
Effect of breed, grazing system and concentrate supplementation on fattening performance, carcass value and meat quality of steers
}

\author{
Matthias Schmutz, Peter Weindl, Salome Carrasco, Gerhard Bellof and Eggert Schmidt \\ Fakultät Land- und Ernährungswirtschaft, Hochschule Weihenstephan-Triesdorf, Freising, Germany
}

\begin{abstract}
The aim of the study was to test the influence of breed, grazing system and concentrate level on fattening performance, carcass value and meat quality of steers.

Ninety-six German Simmental and German Holstein steers were fattened using two different grazing systems: continuous grazing system (CGS) and rotational grazing system (RGS). They were supplemented with medium $(\mathrm{M})$ or low $(\mathrm{L})$ concentrate levels. The trial period involved 22 months divided into four phases: phase 1 (indoor), 2 (grazing), 3 (indoor vs. outdoor) and 4 (grazing). In phases 1 and 3 the animals were offered grass silage ad libitum. All animals were supplied with concentrate during phase 1 . In phases 3 and 4 the animals were supplied with $M$ or L. Group M consumed a total of $275 \mathrm{~kg}$ and group L $191 \mathrm{~kg}$ concentrate per steer.

German Simmental steers were significantly superior in all essential parameters of the fattening performance and the carcass value (e.g. final weight: $631 \mathrm{~kg}$ vs. $608 \mathrm{~kg}$ ). German Holstein steers showed better meat quality (intramuscular fat content, tenderness, meat colour) than German Simmental steers. The impact of the grazing system was only for a few parameters (carcass weight, dressing percentage and fat colour). The CGS showed higher grazing yield and higher content of nutrients than the RGS, as a consequence, CGS steers presented heavier carcass weight than RGS steers. Concentrate levels had no effects on the evaluated parameters.
\end{abstract}

Keywords: steer fattening, rotational grazing system, continuous grazing system, concentrate level, meat quality
Abbreviations: CGS: continuous grazing system, DWG: daily weight gain, GH: German Holstein, GS: German Simmental, IMF: intramuscular fat, L: low, M: medium, NIRS: near-infrared spectroscopy, RGS: rotational grazing system




\section{Introduction}

In the context of structural changes in agriculture, labour and cost extensive cattle fattening on pasture is gaining more and more importance, especially in grassland regions. Recent studies have focused on the effects of feeding practice, sex and genetics on carcass value and meat quality of pasture fattened cattle (e.g. Steen et al. 2003, Keane \& Moloney 2009, Velik et al. 2010a). Studies by Scheeder (2007), Scheeder et al. (2007) and Velik et al. (2009) showed that especially meat from steers can be classified as high quality beef. The reason therefore is in particular a changed hormone metabolism caused by castration which leads to a higher fat concentration in muscle tissue (Schwarz 2003). This increased intramuscular fat (IMF) content has a positive effect on tenderness as well as taste and flavour (Razminowicz et al. 2006).

On a worldwide scale high quality beef is mainly produced by steers. However, on the German beef market meat from intensively fattened young bulls and selected dairy cows predominates. Such intensive production is possible in regions with high maize cultivation. Conversely, in less favoured grassland regions it is necessary to investigate new production alternatives based on natural resources and low additional feedstuffs. Thus, in the last few years the continuous grazing system (CGS) was established in Germany, especially in dairy farming as well as in cattle rearing. The CGS used as intensive permanent pasture is characterized by high yields and high quality of grassland. The rotational grazing system (RGS) can be used as a semi-intensive grazing system (Weindl et al. 2012).

Despite a stagnating per capita consumption of beef in Germany, there is still a growing demand for high quality and sustainably produced beef. This beef is mainly produced by steers or heifers fattened on pasture with high nutrient quality. It is mostly marketed locally or by branded meat programs (Scheeder 2007, Velik et al. 2009).

The purpose of the current study was to develop alternative concepts for beef production based on grassland.

The following questions were investigated in detail:

Which fattening performance and carcass quality can be obtained with German Simmental (GS) and German Holstein (GH) steers reared in a production system based on grass, grass products and the supply of low and medium amounts of concentrate?

Which grazing system (CGS vs. RGS) is suitable for fattening steers?

How does semi-intensive fattening of steers influence the parameters of meat quality?

\section{Material and methods}

The study was conducted at the research station »Zurnhausen« of the University of Applied Sciences Weihenstephan-Triesdorf, near Freising, southern Germany ( $\left.48^{\circ} 26 \mathrm{~N} ; 11^{\circ} 46 \mathrm{E}\right)$, $493 \mathrm{~m}$ above sea level.

\section{Calf purchase and rearing}

A total of 104 bull calves ( 52 GS, 52 GH), delivered by the Producers' Association for Fatstock, Allgäu w.V. (Kaufbeuren, Germany), were stabled in deep litter in October 2010. At the point of purchase the mean age was 4.3 weeks (GS 5.1 weeks, GH 3.5 weeks) and the mean weight was at $71 \mathrm{~kg}$ (GS $76 \mathrm{~kg}, \mathrm{GH} 65 \mathrm{~kg}$ ). Three animals left the group within the first few weeks 
due to health problems. During the first seven weeks the calves received six litres of milk replacer (MR) mixture (125 g MR/I) per day and were weaned at week eight. In addition they were fed with grass silage, hay and concentrate until the fattening period in January 2011. In the rearing phase (101 days) the average feedstuff intake per animal and day was: $750 \mathrm{~g} \mathrm{MR}$, $1.5 \mathrm{~kg}$ concentrate, $1.1 \mathrm{~kg}$ hay and $1.8 \mathrm{~kg}$ grass silage. The mean weight gain was $853 \mathrm{~g} / \mathrm{d}(\mathrm{GH})$ and $909 \mathrm{~g} / \mathrm{d}(\mathrm{GS})$.

\section{Fattening of steers}

The study was designed to compare two different genetic breeds (GS vs. GH), two grazing systems (CGS vs. RGS) and two levels of concentrate (M vs. L). A symmetric set-up (breed, grazing system, concentrate level) was used for the experiment.

The study involved four phases (January 2011 to October 2012; Table 1).

Table 1

Design of the experiment

\begin{tabular}{|c|c|c|c|c|c|c|c|}
\hline Phase & Month & Roughage & $\%$ & Con & entrate level M & Con & centrate level L \\
\hline & & & & $\mathrm{kg} / \mathrm{d}$ & kg/animal/phase & $\mathrm{kg} / \mathrm{d}$ & kg/animal/phase \\
\hline 1 & January-April & Grass silage & 100 & 1 & 75 & 1 & 75 \\
\hline 2 & May-September & Pasture grass & 100 & - & - & - & - \\
\hline & October & Pasture grass & 75 & - & - & - & - \\
\hline & & Grass silage & 25 & - & - & - & - \\
\hline 3 & November-March & Grass silage & 100 & 1 & 152 & 0.25 & 38 \\
\hline 4 & April-August & Pasture grass & 100 & - & - & - & - \\
\hline & September/October* & Pasture grass & 100 & 1 & 28 & 0.5 & 14 \\
\hline
\end{tabular}

*28 days prior to each slaughter

Phase 1 (P-1)

In January 2011, 96 animals were allocated according to breed in 16 pens (fully slatted floor; six animals/pen) at the research station »Hirschau« of the Technical University of Munich (TUM) near Freising. The initial weight of GS was $171 \mathrm{~kg}$ and of GH $157 \mathrm{~kg}$. At the age of five months the animals were bloodlessly castrated. The animals were fed grass silage ad libitum as well as $107 \mathrm{~kg}$ of concentrate (1 kg/animal/day; Table 2). Tables 3 and 4 show the nutritional composition of the grass silage and the concentrate. The grass silage was allotted through a feed mixer. The concentrate was given manually twice a day. The feed intake was registered per pen.

Phase 2 (P-2)

In early May 2011 the animals were randomized to the grazing areas at »Zurnhausen« (CGS and RGS). The animals were divided into two groups (48 animals each, one half each GS and $\mathrm{GH})$. The mean livestock density was 27 animals/ha (RGS) at a mean retention period of four days and eight animals/ha (CGS). The nutritional composition of the pasture is displayed in Table 3. Further information about feed quality of pastures is reported in a previous study by Weindl et al. (2012). Endoparasitic and ectoparasitic treatments were carried out routinely at the beginning (oral administration) and at the end (pour-on preparation) of the grazing season, as well as after a confirmed infestation in mid-summer. 
Table 2

Concentrate composition according to phase (\%)

\begin{tabular}{lcccc}
\hline Feedstuff & P-1 & P-3 & Linseed oil & R-4 \\
& & & 21.1 & 25.0 \\
\hline Grain maize & 49.3 & 42.3 & - & - \\
Wheat grain & 21.7 & 29.4 & - & - \\
Barley & 18.4 & 23.0 & - & - \\
Extruded rapeseed meal & 2.2 & - & - & - \\
Extruded soybean meal & 1.4 & - & 35.1 & 28.6 \\
Soybean hulls & - & - & 26.3 & 21.4 \\
Wheat bran & - & - & 7.2 & 18.4 \\
Molasses pulp (19\% XZ*) & - & - & 2.0 & 2.0 \\
Molasses & - & 1.0 & - & - \\
Rapeseed-Soybean-oil-mixture & 2.0 & - & 4.9 & - \\
Linseed oil & - & - & - & 1.0 \\
Rapeseed oil & - & 4.3 & - & - \\
Mineral mixture (19/5/10/3) & 5.0 & - & 3.5 & 3.6 \\
Mineral mixture (6/6/13/12) & - & &
\end{tabular}

*XZ, raw sugar

Table 3

Nutritional composition of pasture and grass silage according to phase (DM)

\begin{tabular}{lrrrrrrr}
\hline Item & \multicolumn{2}{c}{ CGS } & \multicolumn{2}{c}{ RGS } & \multicolumn{2}{c}{ Grass silage } \\
& P-2 & P-4 & P-2 & P-4 & P-1 & P-3 (I) & P-3 (O)** \\
\hline DM-content, g/kg & 202 & 198 & 210 & 202 & 365 & 485 & 422 \\
Crude ash, g/kg & 108 & 116 & 78 & 92 & 113 & 100 & 98 \\
Crude fat, g/kg & 38 & 33 & 31 & 26 & 34 & 31 & 35 \\
Crude fiber, g/kg & 200 & 207 & 239 & 253 & 253 & 266 & 275 \\
NDForg, g/kg & 445 & 411 & 511 & 493 & 517 & 504 & 524 \\
ADForg, g/kg & 232 & 216 & 278 & 265 & 300 & 300 & 296 \\
ADL, g/kg & 29 & 24 & 33 & 30 & - & - & - \\
Sugar, g/kg & 96 & 85 & 104 & 109 & 37 & 55 & 47 \\
Crude protein, XP, g/kg & 220 & 244 & 172 & 177 & 143 & 153 & 157 \\
Protein solubility, \% von XP & 35.9 & 37.3 & 43.3 & 39.6 & - & - & - \\
Hohenheim Gas Test, ml/200mg & 45.8 & 48.9 & 44.1 & 47.4 & 40.5 & 43.8 & 44.9 \\
Energy, MJ ME/kg & 10.90 & 11.28 & 10.09 & 10.33 & 9.39 & 9.70 & 9.91 \\
\hline
\end{tabular}

*group indoor, ** group outdoor

Table 4

Nutritional composition of the concentrate according to phase (DM)

\begin{tabular}{lcccc}
\hline Item & P-1 & P-3 & \multicolumn{2}{c}{ P-4 } \\
& & & Linseed oil & Rapeseed oil \\
\hline Dry matter, g/kg & 874 & 864 & 895 & 894 \\
Crude ash, g/kg & 68 & 68 & 72 & 75 \\
Crude fat, g/kg & 53 & 39 & 80 & 45 \\
ADForg, g/kg & 42 & 34 & 206 & 215 \\
Starch, g/kg & 601 & 654 & 278 & 284 \\
Crude protein, g/kg & 117 & 97 & 131 & 129 \\
Hohenheim Gas Test, ml/200mg & 57.4 & 53.7 & 53.7 & 52.1 \\
Energy, MJ ME/kg & 13.39 & 12.96 & 12.61 & 11.85 \\
\hline
\end{tabular}


Phase 3 (P-3)

At the end of October, 72 animals were again stabled at the research pen »Hirschau« (group indoor) and 24 animals remained in free-range husbandry at »Zurnhausen« (group outdoor). The husbandry groups »outdoor« and »indoor « had been randomly selected at the beginning of the study, with 24 animals each (in each husbandry group: six GH, six GS, six CGS and six RGS). More detailed information on outdoor husbandry has been published by Weindl et al. (2013). Both groups were offered grass silage ad libitum and restricted amounts of concentrate (group M 1.5 vs. group L $0.75 \mathrm{~kg} /$ animal/day) over a period of 93 days. The outdoor group was offered the medium level $(\mathrm{M})$ using electronic feeding on demand. Two animals from the indoor group were rejected, one due to health problems and the other due to signs of increased reactivation of testis.

\section{Phase 4 (P-4)}

In spring (April 2012) the animals were relocated to the grazing areas. The groups remained the same as in P-2, as well as the anti-parasite treatment. The mean livestock density was 14 animals/ha (RGS) at a retention period of seven days and five animals/ha (CGS). In addition to pasture a mixture of minerals was supplied ad libitum (licking bowls). 28 days prior to slaughtering concentrate was fed according to their grouping in P-3 by electronic feeding on demand. The concentrate mixtures in P-4 differed in composition (linseed oil vs. rapeseed oil) in order to intentionally alter the fatty acid composition of the carcasses (Table 4).

\section{Data collection}

\section{Feedstuff}

The nutritional compositions of pasture, silage and concentrate are shown in Table 3. They were analysed according to the near-infrared spectroscopy (NIRS)-method and AOAC (1990). Additional detailed information on the methods and sampling as well as on pastures and natural landscape units can be found at Weindl et al. (2012). A sample was taken from each grass silage feedstuff mixture and the dry matter (DM) was analysed. Samples were collected every 14 days, mixed and analysed at the laboratory of the Board of Trustees of the Producers' Association for Animal Husbandry Bavaria (LKV) of the Bavarian State Research Centre for Agriculture ( $\mathrm{LfL}$ ) in Grub. For the arithmetic average please refer to Table 3. The composition and the components of the concentrates used can be found in Tables 2 and 4 . These were analysed by the TUM-Bioanalytik in Weihenstephan.

\section{Animal data}

All animals were weighed monthly. The last weighing was conducted on the day before slaughter and represents the final weight.

\section{Slaughter}

After a fasting period of $24 \mathrm{~h} 94$ steers were slaughtered at the research slaughterhouse of the Bavarian State Research Centre for Agriculture $(\mathrm{LfL})$ in Poing-Grub. Prior to the slaughter the animals were weighed. The weight of kidney fat and the carcass weight of the warm carcass were recorded. The classification of the carcasses was carried out according to the 
EUROP-scheme (15-point scale). After slaughter the carcasses were cooled to $2-4^{\circ} \mathrm{C}$ for $24 \mathrm{~h}$. The cold carcass weight, the carcass length, the leg parameter, the leg spiral dimension, the longissimus area and the pistol weight were determined. The marbling was defined at the cut surface of the pistol according to a 5-point scale. For quality determinations of meat quality samples of $M$. longissimus dorsi between the 9 th and 10 th ribs were collected, likewise approximately $500 \mathrm{~g}$ of the $M$. semitendinosus were extracted.

\section{Meat quality}

To determine meat and fat colour a spectrophotometer (Minolta CM-508i, Konica Minolta, Marunouchi, Japan) was used. The colour values are given according to the $L^{*} a^{*} b$-system (CIELAB-system, CIE 1976). The fat colour was determined in a fresh cut area at the leg. The meat colour of the $M$. longissimus dorsi was also determined with a fresh cut $24 \mathrm{~h}$ after slaughter. The IMF was determined through NIRS measuring of the M. longissimus dorsi samples (9th rib). Samples with similar NIRS test results were then analysed in a wet chemical analysis (acid hydrolyses with extraction of soxhlet, modified method according to $\S 35 \mathrm{LMG}$, $\mathrm{L}$ 06.00-6). To determine the tenderness, a $2.5 \mathrm{~cm}$ wide slice from each muscle sample $(M$. longissimus dorsi (10th rib) and $M$. semitendinosus) was vacuum-sealed in a plastic bag and, after weighing, stored at $4{ }^{\circ} \mathrm{C}$ in a refrigerator with air circulation for 13 days. After 13 days the weight reduction through storage was determined. The $\mathrm{pH}$-value was then measured. The samples were cooked in hot water up to a core temperature of $70^{\circ} \mathrm{C}$. After cooling down for an hour the reduction through cooking was determined. After $24 \mathrm{~h}$ storage in a refrigerator 10 single samples were taken per muscle sample and cut in fibre direction with a double-bladed scalpel (sample diameter $1 \times 1 \mathrm{~cm}$ ). To determine tenderness, the shear force was measured with an Instron (type 4301). Evaluated were Warner-Bratzler shear force at maximum level (in $\mathrm{N})$ and shear force (in $\mathrm{kg} / \mathrm{cm}^{2}$ ).

\section{Statistical analysis}

The data were statistically analysed with the software SPSS v20.0 (IBM, New York, USA). All parameters were subjected to a three-factorial analysis of variance according to the General Linear Model. The following statistical model was used:

$$
Y_{i j k}=\mu+A_{i}+B_{j}+C_{k}+b\left(x_{i j k}-\right)+e_{i j k}
$$

where $Y_{i j k}$ is the observed value of $i_{j k}$ animal, $\mu$ is the population average, $A_{i}$ is the fixed effect of the $i$ breed (GS, GH), $B_{j}$ is the fixed effect of the $j$ grazing system (CGS, RGS), $C_{k}$ is the fixed effect of the $k$ concentrate level $(M, L), b$ is the partial regression on the age of the animals (except for initial weight in $\mathrm{P}-1$ ) and $e_{i j k}$ is the residual error.

Differences were each tested by means of the F-test. After robust F-test results the means were compared by use of the Tukey-test. An interaction between factors was not shown. The growth pattern for both breeds was described by using a cubic regression:

$$
y=a+b x+c x^{2}+d x^{3}
$$

where $y$ is the body weight of animal and $x$ is the age. 


\section{Results}

\section{Feedstuff}

Table 3 shows components and feed value of samples from pasture and grass silage. It shows that the energy and crude protein contents of the samples from pasture are higher in P-4 than in P-2. Additionally the CGS pasture presented better nutritional quality than RGS pasture. The yields in P-2 were $13.5 \mathrm{t} / \mathrm{ha}$ (CGS) and 10.7t/ha (RGS). The nutritional composition of the grass silage was similar, except for P-1; it corresponded to another harvest period. The components of the concentrate mixtures for P-1 and P-3 were nearly identical (Table 4). In P-4 concentrates two different lipids (fatty acid composition) were used (linseed vs. rapeseed). The set of fat components resulted in different metabolic energy levels. These differences did not impact the analysed parameters in the present study.

\section{Feedstuff intake}

The animals' average feed intake according to the phase results are summarized in Table 5. The total concentrate intake over the whole fattening period was $191 \mathrm{~kg}$ per steer for group L and at $275 \mathrm{~kg}$ per steer for group M. However, 13 animals (five GS and eight GH) had difficulties accepting the feeding station in P-4, for this reason they consumed less than $6 \%$ of the supplied concentrate during this final phase. In reference to the total metabolic energy intake, the concentrate accounts for about $5.1 \%$ in group $M$ and $3.6 \%$ in group $L$ of the total intake of the ME.

\section{Fattening performance}

Figure 1 represents the growth development of live weight of GS and GH steers with a regression curve $\left(\mathrm{R}^{2}=0.98\right.$ for $\mathrm{GS}$ and $\left.\mathrm{GH}\right)$. German Simmental steers show in P-2, P-3 and P-4 higher daily weight gain (DWG) than GH (740 vs. $720 \mathrm{~g} ; 780$ vs. $730 \mathrm{~g} ; 960$ vs. $850 \mathrm{~g}$ ). The same trend was observed in the LS mean values (789 vs. $736 ; 754$ vs. $685 ; 750$ vs. 687 g). Nevertheless, the obtained DGWs in P-4 through the regression curves were higher than the LS mean values. Table 6 describes the results of the fattening performance. German Simmental breed showed significantly better results in all parameters of the fattening performance $(P<0.05)$; except

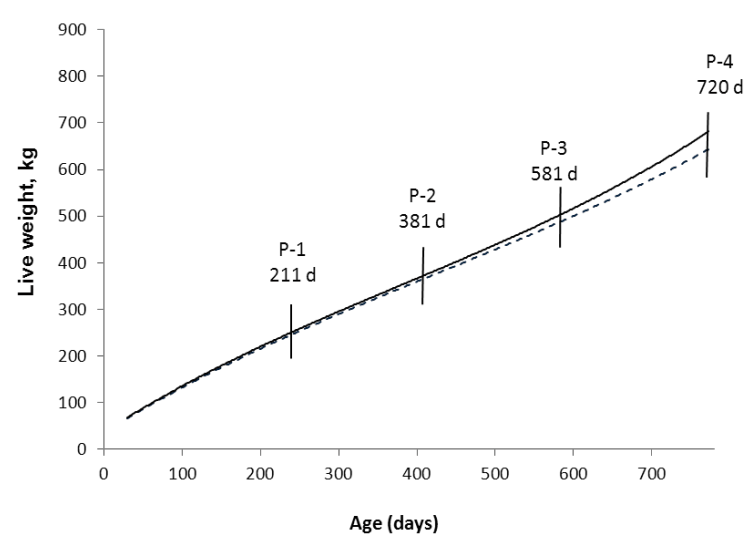

$\mathrm{FV}=37.16+1.08 \mathrm{x}+9.73 \times 10-4 \times 2-$ $8.52 \times 10-8 \times 3(R 2=0.98)$

$\mathrm{DH}=37.00+1.03 \mathrm{x}+8.27 \times 10-4 \times 2-$ $6.55 \times 10-8 \times 3\left(R^{2}=0.98\right)$

Figure 1

Growth pattern of German Simmental steers (solid line) and German Holstein steers (broken line) according to phases 
for the initial weight in P-2 and for the weight after the period of fasting. The development described in Figure 1 resulted in a significantly higher final weight in favour of breed GS. The targeted final weight of $625 \mathrm{~kg}$ was exceeded by $6 \mathrm{~kg}$ by the group GS, while group GH undercut it by $17 \mathrm{~kg}$. In reference to the actual age at slaughter the two groups differed by only three days (GS 742 vs. GH 745 days of age). In regard to the grazing system, animals of the CGS showed higher initial weight in P-4 than animals of the RGS. The levels of concentrate had no significant effect on the studied parameters.

\section{Carcass value}

The results of the carcass value are displayed in Table 7. All the studied parameters were affected for breed, except the net weight gain and kidney fat. German Simmental animals presented higher values than $\mathrm{GH}$ animals. The grazing system significantly influenced only the carcass weight and the dressing percentage. In both cases group CGS is superior to group RGS. Animals of CGS tend to show a higher pistol weight (70.1 vs. $68.9 \mathrm{~kg}$ ), a larger longissimus area (54.5 vs. $52.3 \mathrm{~cm}^{2}$ ) as well as a better conformation score (5.7 vs. 5.2 points). Level of concentrate did not significantly impact any of the parameters listed in Table $7(P>0.05)$.

\section{Meat quality}

In regard to the meat quality $\mathrm{GH}$ steers showed a significantly $(P<0.05)$ higher IMF content (3.89 vs. $2.47 \%$ ) and marbling (2.77 vs. 2.09 points) than GS steers, as could be observed in Table 8. In the M. longissimus dorsi evaluated parameters, animals of the breed GH showed significantly $(P<0.05)$ lower tenderness values: WBSF max. (66.35 vs. $82.95 \mathrm{~N})$ and shear force ( $4.89 \mathrm{vs} .6 .11 \mathrm{~kg} / \mathrm{cm} 2)$, than animals of the breed GS. However, this effect could not be observed in the M. semitendinosus ( $P>0.05$ ). The meat of breed GS showed a significantly higher cooking loss (25.93 vs. $24.70 \%)$. In regard to meat colour, the breed GH showed significantly higher $a^{*}$ and $b^{*}$ values (13.32 and 3.49 vs. 12.79 and 2.65). German Holstein steers had a significantly lighter and more yellow fat colour ( 64.49 and 14.16 vs. 63.83 and 12.83). The grazing system impacted only the fat colour (CGS higher yellowness $b^{*}$, RGS higher $L^{*}$ value).

Table 5

Grass silage, pasture and concentrate intake (kg DM/d) according to phase

\begin{tabular}{lllllc}
\hline Feedstuff & Phase & \multicolumn{2}{c}{ Breed } & \multicolumn{3}{c}{ Grazing system } \\
& & GH & GS & CGS & RGS \\
\hline Grass silage & 1 & 4.5 & 4.6 & - & - \\
Concentrate & 1 & 0.85 & 0.85 & 0.85 & 0.85 \\
Pasture grass & 2 & - & - & 6.9 & 7.1 \\
Grass silage (Indoor)1 & 3 & 8.9 & 9.1 & 9.0 & 8.9 \\
Grass silage (Outdoor)2 & 3 & 9.5 & 9.5 & - & - \\
Concentrate (Indoor) Medium & 3 & 0.61 & 0.61 & 0.61 & 0.61 \\
Concentrate (Indooor) Low & 3 & 0.31 & 0.31 & 0.31 & 0.31 \\
Concentrate (Outdoor) & 3 & 0.51 & 0.55 & 0.53 & 0.50 \\
Pasture grass & 4 & - & - & 11.6 & 12.6 \\
Concentrate Medium* & 4 & 0.74 & 0.71 & 0.70 & 0.75 \\
Concentrate Low* & 4 & 0.28 & 0.31 & 0.26 & 0.34 \\
\hline
\end{tabular}

*28 days prior to each slaughter 

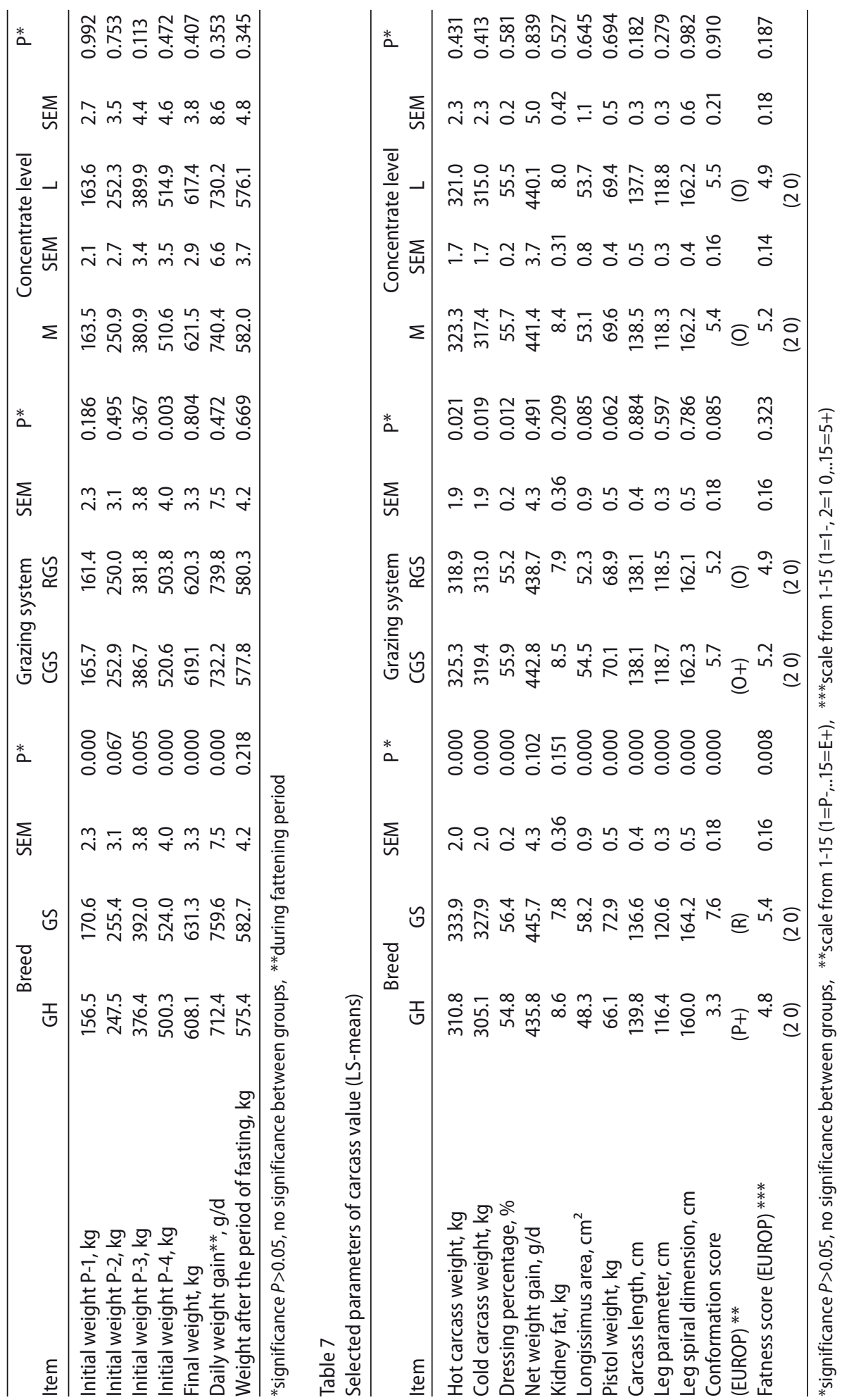


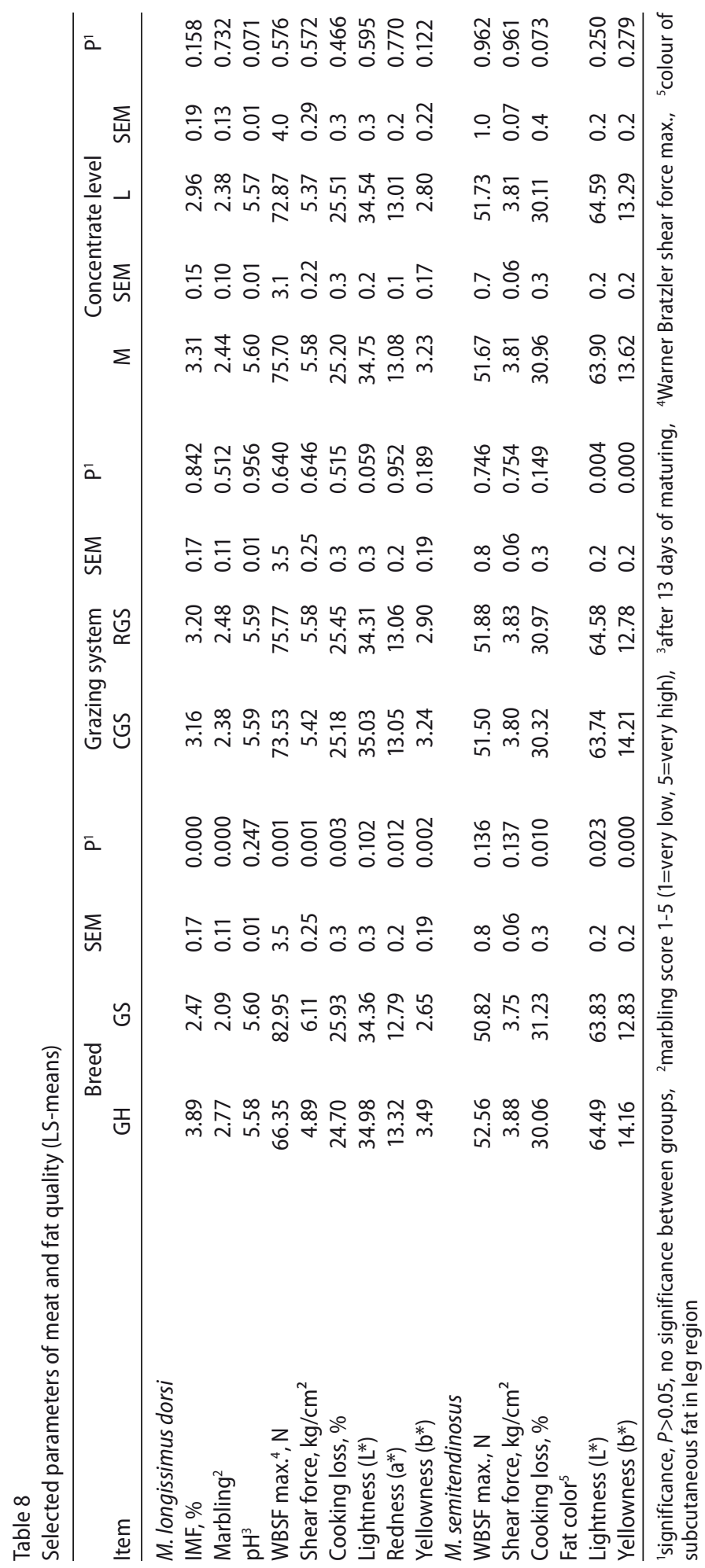




\section{Discussion}

\section{Fattening performance}

The genotype has a decisive effect on the fattening performance and the carcass value of fattened animals as it was shown by Chladek \& Ingr (2003) and Nuernberg et al. (2005). They reported that final weights were lower than the reached final weights in the present study at the same age. To reach a high final weight appropriate feedstuff intake and DWGs are necessary. A significant impact of breed on the DWG has already been observed by Nuernberg et al. (2005). The grazing system does influence the fattening performance as either. Parameters like livestock density, yield, average height, vegetative stage and species composition influence significantly the DWG of fattened animals (Chassot \& Troxler 2006, Fraser et al. 2009). Chassot \& Troxler (2006), Fraser et al. (2009) as well as Steen et al. (2003) reached significantly higher DWGs in crossbred steers. Keane \& Moloney (2009) on the other hand describe results similar to the present study. However, when continuous grazing system and rotational grazing system were compared in the study of Häusler et al. (2006), heifers generally showed considerably higher DWGs than the steers in this study. The conspicuously low DWGs on CGS in P-2 were on the one hand caused by an extended dry period which led to a low average height of the pasture and on the other by an established infestation with endoparasites in group CGS, which had to be treated, despite a precautionary deworming treatment. Except the initial weight in P-4, no significant differences between both grazing systems were detected, as far as the parameters for the fattening performance are concerned, which is in accordance with Häusler et al. (2006). The generally higher fattening performance of group CGS was consistent with the higher nutritional value of the pasture in this grazing system (Table 3).

In contrast Thomet et al. (2000) described a yield which is up to $8 \%$ lower on CGS compared to RGS. For the authors the targeted average height of growth on pasture of $6-8 \mathrm{~cm}$ was in part considerably undercut due to the high feedstock density. Despite a relatively high feedstock density, especially in P-4, the present study shows a sustained increase in DWGs on both grazing systems. While it is true that by significantly undercutting the average height the fattening performance deteriorates, the yield per unit though rises and therefore the animals can still absorb enough biomass to transpose into meat, provided the feedstock density is kept low (Parsons et al. 1983, Yarrow et al. 1996).

\section{Carcass value}

While the dual purpose breed GS invests absorbed nutrients into a higher meat accretion, dairy breeds like GH use them for increased organ and bone growth (Breier \& Sauerwein 1995, Pfuhl et al. 2007). This fact significantly impacts, besides the fattening performance, almost all studied parameters of the carcass quality. The results for the carcass yield are in accordance with results that Warzecha et al. (1999) showed for bulls. The obtained values of net weight gain were similar to those observed by Scheeder et al. (2007). Similarly the weight of kidney fat and the longissimus area were consistent with the reports by Frickh (2001a). The results for the conformation score of the breed GS can also be found at French et al. (2001) and Keane \& Moloney (2009) for crossbred steers of a meat breed kept on pasture. French 
et al. (2001) described a higher fatness score but Keane \& Moloney (2009) showed similar results to the reached values in this study. According to Steen et al. (2003), Keane \& Moloney (2009) and Velik et al. (2010a) pasturing steers and heifers ordinarily result in a lower fat cover of the carcass and a decreased conformation, which is in accordance with the results for $\mathrm{GH}$ breed. One reason for the significant effect of grazing system on carcass weight and dressing percentage could be the animals' differing amounts of feedstuff intake. While it takes the animals on CGS a relatively long time to intake feedstuff due to the low average height of the pasture, these animals rarely reach a rumen fill comparable to animals on RGS. This implies that the ruminal passage rate in CGS group was higher and the loss through fasten must be smaller than in the group RGS, which turned out to be true. This assumption might possibly prove why the group RGS reached a lower final weight, as the proportionate weight loss after fasting period is higher due to a better rumen fill. Another reason is the better quality of CGS pasture. Wiegand et al. (2006a) pointed out that the different composition of pasture grass and leguminous crops could be a possible cause. The calculation of the allotted amounts of concentrate were done according to Chassot \& Dufey $(2006,2008)$, in order to save on concentrate. However as a result, the low amount of concentrate (M: $275 \mathrm{~kg} / \mathrm{animal} ; \mathrm{L:} 191 \mathrm{~kg} /$ animal) neither significantly impacted the parameters of the fattening performance nor those of the carcass quality.

\section{Meat quality}

The significant effect of breed on the IMF content and on the measured parameters in $M$. longissimus dorsi are similar to the findings of Frickh (1997) and Nuernberg et al. (2005) with higher contents for GH breed. The observed low shear force value of GH was consistent with its high IMF content. While Roffeis et al. (1999) observed similar results, Frickh (2001a), Chambaz et al. (2003) and Velik et al. (2010b) found lower values. These differences are likely due to the different measuring methods. Additionally, it is probably insufficient meat maturation, although reductions of $\mathrm{pH}$-value and juice retention properties do not indicate that. However, according to Wiegand et al. (2006b) the meat of extensively fattened animals generally has a delayed meat maturation compared to intensively fattened animals. This might possibly have led to lower results. In this study had the measuring been done after a prolonged meat maturation. The lower daily weight gains in pastured animals and thereby the higher age at slaughter can be eliminated as the main cause of high shear force values, at least according to the studies done by Velik et al. (2009) and Scheeder et al. (2007). Moloney et al. (2011) similarly were not able to detect increased shear force values for cattle fattened on pasture after 14 days of meat maturation. Lower levels of drip loss and grilling loss of GH bulls in comparison to GS bulls were also shown by Frickh (1997). Branscheid \& Augustini (1991) showed that the $M$. semitendinosus features a higher grilling loss in comparison to the M. longissimus dorsi, which here in turn might be applied to the correspondingly higher cooking losses in the $M$. semitendinosus. In regard to the meat colour, the lightness values of the meat were similar to those observed by Kim et al. (2003) and Frickh (2001a). Contrary to our findings, Szücs et al. (2001) did not report on differences between breeds for a*. However, Frickh (1997) as well states differences between breeds for $a^{*}$ (GH 5.4 vs. GS 4.2) but they were lower compared to our findings. Probably the high values are due to the animals' age 
(Priolo et al. 2001) or due to the measuring methods. The observed darker meat colour in this study had already been shown by other authors (Schwarz 2003, Nuernberg et al. 2005), with pastured animals. Whether this was caused by the animals' age (Schwarz 2003) or by a higher myoglobin concentration in the pastured animals' muscle (Nuernberg et al. 2005) remains unclear. An influence of breed on meat yellowness could not be confirmed in the literature for the studied breeds. Only Frickh (2001b) has conducted a comparison of breeds (GS vs. Pinzgauer) and found higher $b^{*}$ values in Pinzgauer animals. The higher $b^{*}$ values obtained in the meat of $\mathrm{GH}$ in the present study were related with its higher IMF content.

In regard to fat colour, similar results were found in the studies of Frickh (2001a) and Velik et al. (2009). The significantly higher values for the breed GH can be explained by the works of Walker et al. (1990) and Barton \& Pleasents (1993), according to whom dairy breeds display a markedly more yellow fat colour than meat breeds do. In general the intensive fat yellow colour of pastured animals was caused by the high carotenoid content of forage (Noziere et al. 2006, Dunne et al. 2006). The reason for the significant effect of grazing system on the fat colour was consequently caused by an elevated $\beta$-carotene intake of animals from CGS group. Noziere et al. (2006) summarized that the carotenoid concentration decreases with forage age. That implies that as a result of its lower age the CGS pasture contained a higher share of foliage compared to RGS pasture and involved a higher content of nutrients and consequently a higher content of $ß$-carotenes.

In conclusion, pasture based fattening of steers with low allowances of concentrate yielded satisfactory results for the fattening performance and the carcass quality. While steers of the breed German Simmental showed superiority in these parameters, the meat of German Holstein steers displayed an improved meat quality. The grazing system has a limited impact on the mentioned parameters. Due to the higher nutritional value of the pasture, animals reared on continuous grazing system showed slightly better carcass values. The low and differing provisions of the supplementary concentrate (L: 191; M: $275 \mathrm{~kg}$ per steer) did not have any influence on the evaluated parameters.

\section{Acknowledgements}

The present study was funded by the BMBF programme »FhprofUnt« (project No. $17090 \times 10$ ).

\section{References}

AOAC (1990): Official Methods of Analysis. 15th ed., Association of Official Analytical Chemists, Arlington, VA, USA

Barton RA, Pleasents AB (1993) Fat colour and meat colour in different breeds of steers in five consecutive years raised on pasture and slaughtered at 30 months of age. Proc N Z Soc Anim Prod 53, 389-392

Branscheid W, Augustini C (1991) [Meat quality and its biological fundamentals in fattened beef]. Final report of the Federal Institute of Meat Research, Kulmbach, Germany [in German]

Breier BH, Sauerwein H (1995) Regulation of growth in ruminants by the somatotropic axis. In: Engelhardt W, Leonhard-Marek S, Breves G, Giesseke D (eds.) Ruminant physiology: digestion, metabolism, growth and reproduction. Proc 8th Int Symp Rumin Physiol, Willingen (Germany) 25-30 September 1994, Stuttgart, Germany, 102-123 
Chambaz A, Scheeder MRL, Kreuzer M, Dufey PA (2003) Meat quality of Angus, Simmental, Charolais and Limousin steers compared at the same intramuscular fat content. Meat Sci 63, 491-500

Chassot A, Dufey PA (2006) [Finishing of steers following a summering period on mountain pastures: effect of the finishing duration on fattening performance]. Agrarforschung 13, 470-475 [in German]

Chassot A, Dufey PA (2008) [Finishing of steers following a summering period on mountain pastures: effect of feeding intensity on fattening performance]. Agrarforschung 15, 372-377 [in German]

Chassot A, Troxler J (2006) [Extensive steer fattening including a summering period]. Agrarforschung 13, 374-379 [in German]

Chládek G, Ingr I (2003) Meat quality and beef production parameters of Holstein steers fattened up 10-12 months of age. Czech J Anim Sci 48, 474-480

CIE (1976) Colorimetry. 2nd ed., Commision International de l'Eclairage, Vienna, Austria

Dunne PG, O'Mara FP, Monahan FJ, Moloney AP (2006) Changes in colour characteristics and pigmentation of subcutaneous adipose tissue and $M$. longissimus dorsi of heifers fed grass, grass silage or concentratebased diets. Meat Sci 74, 231-241

Fraser MD, Davies DA, Vale JE, Nute GR, Hallett KG, Richardson RI, Wright IA (2009) Performance and meat quality of native and continental cross steers grazing improved upland pasture or semi-natural rough grazing. Livest Sci 123, 70-82

French P, O'Riordan EG, O'Kiely P, Caffrey PJ, Moloney AP (2001) Intake and growth of steers offered different allowances of autumn grass and concentrates. Anim Sci 72, 129-138

Frickh JJ (1997) [Qualitative characteristics of beef and a comparison of breeds in reference to the age at slaughter]. Dissertation, University of Vienna, Austria [in German]

Frickh J (2001a) [Influence of feeding intensity on the fattening performance and the carcass quality as well as the meat quality in the fattening of steers and heifers]. Final report research project no. 1127. Agricultural Experimental Stations GmbH, Wieselburg, Austria [in German]

Frickh JJ (2001b) [Adaptation of research methods for routine testing of meat quality in the context of stationary tests]. Final report research project no. 1168. Agricultural Experimental Stations GmbH, Wieselburg, Austria [in German]

Häusler J, Velik M, Steinwidder A, Gasteiner J, Resch R, Eingang D (2006) [Comparison of grazing systems: Short grass pasture - Couple pasture]. Final report. Research and Education Centre Raumberg-Gumpenstein, Irdning, Austria [in German]

Keane MG, Moloney AP (2009) A comparison of final systems and duration for spring-born Aberdeen Angus $\times$ Holstein-Friesian and Belgian BluexHolstein-Friesian steers. Livest Sci 124, 223-232

Kim YS, Yoon SK, Song YH, Lee SK (2003) Effect of season on colour of Hanwoo (Korean native cattle) beef. Meat Sci 63, 509-513

Moloney AP, Mooney MT, Troy DJ, Keane MG (2011) Finishing cattle at pasture at 30 months of age or indoors at 25 months of age: Effects on selected carcass and meat quality characteristics. Livest Sci 141, 17-23

Nozière P, Graulet B, Lucas A, Martin B, Grolier P, Doreau M (2006) Carotenoids for ruminants: From forages to dairy products. Anim Feed Sci Technol 131, 418-450

Nuernberg K, Dannenberger D, Nuernberg G, Ender K, Voigt J, Scollan ND, Wood JD, Nute GR, Richardson RI (2005) Effect of a grass-based and a concentrate feeding system on meat quality characteristics and fatty acid composition of longissimus muscle in different cattle breeds. Livest Prod Sci 94, 137-147

Parsons AJ, Leafe EL, Collett B, Penning PD, Lewis J (1983) The Physiology of Grass Production Under Grazing. II. Photosynthesis, Crop Growth and Animal Intake of Continuously Grazed Swards. J Appl Ecol 20, 127-139

Pfuhl R, Bellmann O, Kühn C, Teuscher F, Ender K, Wegner J (2007) Beef versus dairy cattle: a comparison of feed conversion, carcass composition, and meat quality. Arch Tierz 50, 59-70

Priolo A, Micol D, Agabriel J (2001) Effects of grass feeding systems on ruminant meat colour and flavour. A review. Anim Res 50, 185-200

Razminowicz RH, Kreuzer M, Scheeder MRL (2006) Quality of retail beef from two grass-based production systems in comparison with conventional beef. Meat Sci 73, 351-361 
Roffeis M (1999) [High yields and the best management are prerequisites for good marketing opportunities]. [Contributions to the Day of the Beef Cattle: Requirements in regards to a market oriented beef production], Gross Kreutz, Germany, 58 [in German]

Scheeder MRL (2007) [Studies on meat quality of pastured organic beef in reference to the influence of the animals' age at slaughter and in comparison to high quality beef]. Final report. ETH Zürich, Institute of Animal Sciences, Zürich, Switzerland [in German]

Scheeder MRL, Meili E, Bezencon M, Spring J, Kreuzer M (2007) [Relationship between the age of cattle and steers fattened on pasture and parameters of meat texture (tenderness)]. In: Kreuzer M, Wenk C (eds.) [Series of studies Institute of Animal Sciences], ETH Zürich, Institute of Animal Sciences, Zürich, Switzerland, vol. 29, 140-143 [in German]

Schwarz FJ (2003) [Effects of nutrition on quality of beef]. Zuchtungskunde 75, 357-367 [in German]

Steen RWJ, Lavery NP, Kilpatrick DJ, Porter MG (2003) Effects of pasture and high-concentrate diets on performance of beef cattle, carcass composition at equal growth rates, and the fatty acid composition of beef. N Z J Agric Res 46, 69-81

Szücs E, Ender B, Papstein HJ, Nürnberg G, Ender K (2001) [Comparison of carcass and nutritional value as well as meat quality of young bulls of the breeds German Simmental and German Holstein (Dapple Black) in the course of growth. 2. posting: Nutritional value and meat quality]. Züchtungskunde 73, 45-53 [in German]

Thomet P, Hadorn M, Troxler J (2000) [Benchmarking short grass and couple pasture with steers]. Agrarforschung 7, 472-477 [in German]

Velik M, Kitzer R, Kaufmann J, Eingang D (2009) [Meat quality and fatty acid composition of Austrian beef branding programs]. Final report beef label. Research and Education Centre Raumberg-Gumpenstein, Irdning, Austria [in German]

Velik M, Friedrich EM, Häusler J, Kitzer R, Kaufmann J, Adelwöhr A, Steinwidder A (2010a) [Fattening heifers on pasture - fattening performance, carcass quality and meat quality]. Livestock conference, Irdning, Austria, 57-64 [in German]

Velik M, Gangnat I, Friedrich EM, Kitzer R, Häusler J (2010b) [Results of beef production on pasture - heifer, steer, young cattle]. Conference on organic farming, Research and Education Centre Raumberg-Gumpenstein, Irdning, Austria, 45-50 [in German]

Walker PJ, Warner RD, Winfield CG (1990) Sources of variation in subcutaneous fat colour of beef carcasses. Proc Aust Soc Anim Prod 18, 416-419

Warzecha H, Löhnert HJ, Müller J (1999) [Guideline for the efficient and environmentally sound production of beef from bulls and steers]. Thuringian State Institute of Agriculture, Jena, Germany [in German]

Weindl P, Luderschmid C, Bellof G (2012) [Comparative studies on the nutritional content and feed value of growth on continuous grazing system and rotational grazing system]. In: Fahn C, Windisch W (eds.) [Perspectives of a resource-efficient and sustainable animal nutrition]. 50th annual meeting of the Bavarian Association for Animal Nutrition e.V., Freising, Germany, 110-115 [in German]

Weindl P, Bellof G, Schmidt E (2013) [Comparative studies on the economic viability of year-round free range husbandry compared to indoors husbandry during the winter of fattened steers of different breeds, taking into account a grassland based feeding regimen]. In: Proc 125th VDLUFA Congress, Berlin, VDLUFA (ed.), Darmstadt, Germany [in German] accepted

Wiegand D, Schnäckel W, Schnäckel D, Fahr RD, Knape C, Heckenberger G (2006a) [Meat quality from cattle kept with extensive grazing - 1. Collection and comparison of quantitative and slaughter relevant parameters in reference to the feeding regimen, sex, genotype]. Fleischwirtschaft 86, 98-104 [in German]

Wiegand D, Schnäckel W, Schnäckel D, Fahr RD, Knape C, Heckenberger G (2006b) [Meat quality from cattle kept with extensive grazing 2. Technological aspects and properties]. Fleischwirtschaft 86, 91-96 [in German]

Yarrow NH, Penning PD, Johnson RH (1996) The effect of plane of winter nutrition and sward height on the performance of steers grazing grass/white clover swards. Grass Forage Sci 51, 424-433 